\title{
Expression levels and significance of miR-184 and miR-126 in burned rats
}

\author{
SIDA XU*, YOUFEN FAN", TIANBIN WU and PEI XU \\ Department of Plastic and Burn Surgery, Ningbo No. 2 Hospital, Ningbo, Zhejiang 315010, P.R. China
}

Received November 26, 2018; Accepted April 12, 2019

DOI: $10.3892 /$ etm.2019.7578

\begin{abstract}
Expression levels and significance of miR-184 and miR-126 in burned rats were investigated. A total of 30 healthy rats were selected to construct a burn rat model, and another 10 healthy rats as the control group. The modeled rats were divided into groups I, II and III according to burn area, 10 for each group. The reverse transcription-quantitative polymerase chain reaction (RT-q.PCR) was used to detect the expression of miR-184 and miR-126 in the serum of three groups of burned rats, and ELISA was employed to detect the expression levels in peripheral blood and the correlation. There was no difference in the expression levels of miR-184 and miR-126 among the four groups of rats before modeling ( $>0.05)$. Those of miR-184 and miR-126 at each time point were lower than those at the previous one in groups I, II and III $(\mathrm{P}<0.05)$. There was no significant change in the expression levels of miR-184 and miR-126 in the control group $(\mathrm{P}>0.05)$. At the same time point, those of miR-184 and miR-126 decreased with the increase of burn degree, and the difference was statistically significant between every two groups $(\mathrm{P}<0.05)$. The results of Pearson's correlation analysis revealed that the expression level of miR-184 was positively correlated with that of miR-126 $(r=0.832, \mathrm{P}=0.002)$. miR-184 and miR-126 were positively correlated with burn degree $(\mathrm{r}=0.901, \mathrm{P}=0.001, \mathrm{r}=0.775, \mathrm{P}=0.001)$ and time after burn $(\mathrm{r}=0.732, \mathrm{P}=0.004, \mathrm{r}=0.753, \mathrm{P}=0.002)$. The expression levels of miR-184 and miR-126 decrease in burned rats. The changes of their levels may be used as a reference standard for clinical efficacy evaluation to evaluate burn degree, preventing burn wounds from deepening.
\end{abstract}

Correspondence to: Dr Pei Xu, Department of Plastic and Burn Surgery, Ningbo No. 2 Hospital, 41 Xibei Street, Ningbo, Zhejiang 315010, P.R. China

E-mail: pyf6v9@163.com

*Contributed equally

Key words: burned rat, miR-184, miR-126, expression level, correlation

\section{Introduction}

Burns, a series of complex pathophysiological changes caused by heat such as high-temperature gas, liquid and solid, can cause skin tissue damage, pain, loss of tissue fluid and wound necrosis, resulting in systemic infection and even death (1). Burn wounds, often have deeper burn phenomenon, so avoiding burns is very important (2). After severe burns, the increase in capillary permeability leads to severe inflammatory response. The formation and release of a large number of inflammatory mediators plays an important role in burned rats (3). The sustained or excessive release of inflammatory mediators can lead to a variety of inflammatory effects, cells activating the coagulation system and complement activation, which causes damage to endothelial cells and distant organs (4). As a power organ of circulation, the structural and functional damage to the heart will inevitably promote the occurrence and development of burn shock, having become one of the important factors of early ischemic hypoxia (5). The prevention and treatment of myocardial damage after burns is very important during burn treatment. Studies have shown that the application of stem cells in local hypoxic myocardial tissues can effectively improve the viability of damaged myocardial cells, repair damaged myocardial tissues, and partially improve myocardial function (6). With low immunogenicity, multi-directional differentiation, easy separation and proliferation, mesenchymal stem cells (MSCs) provide a new treatment method for severe burns (7). Expressing in the tissues of burned rats, miR-184 and miR-126 are also abnormally expressed in the process of neovascularization, suggesting that they may be involved in the formation of neovascularization (8). It is suggested that they may protect the regulation of early burned myocardial injury. Studies have shown that involved in key gene regulation, miR-184 and miR-126 may be highly expressed in angiogenesis and endothelial cells, regulating angiogenesis via cell signaling pathways such as VEGF (9). The abnormal expression is expected to become a new target for neovascularization therapy (10).

In this study, miR-184 and miR-126 were studied to investigate their expression changes in burned rats and their correlation analysis.

\section{Materials and methods}

Experimental objects. A total of 40 healthy SD rats (provided by the Experimental Animal Center of Guangxi Medical 
Table I. Primer sequences.

Upstream primer

Downstream primer

$\begin{array}{ll}\text { miR-184 } & \text { 5'-ATCCAGAGACAAGACATGTAC-3' } \\ \text { miR-126 } & \text { 5'-TGGCGGTTTGCGGTGGAC-3' } \\ U 6 & \text { 5'-CGCTTCGGCAGCACATATAC-3' }\end{array}$

5'-TTCAGATGTTCTAAGCCTACGG-3'

5'-CCAGTGCAGGGTCCGAGGT-3'

5'-TTCACGAATTTGCGTGTCAT-3'

University, Guangxi, China) were divided into 4 groups, with a body mass of $200 \pm 20 \mathrm{~g}$, including male and female, 10 for each group. The groups were: normal control, model I, model II and model III groups. The difference was not statistically significant concerning sex, age and body weight in the four groups of rats $(\mathrm{P}>0.05)$ (data not shown).

This study was approved by the Ethics Committee of Ningbo No. 2 Hospital (Ningbo, China).

Reagents and instruments. PCR kit was purchased from Thermo Fisher Scientific (China) Co., Ltd., Shanghai, China; RPMI-1640 medium from Gibco; Thermo Fisher Scientific, Inc., Waltham, MA, USA; $10 \%$ fetal bovine serum from Shanghai Harling Biotechnology Co., Ltd., Shanghai, China; Thiazolyl Blue (MTT) and dimethyl sulfoxide (DMSO) from Suzhou Lianxiong Chemical Technology Co., Ltd., Suzhou, China; 3.5\% chloral hydrate from Qingdao Yulong Seaweed Co.,Ltd., Qingdao, China; Olympus IX71 inverted fluorescence microscope from Beijing Presisi Instrument Co., Ltd., Beijing, China; YLS-5Q desktop super temperature control scald instrument from Beijing Ruiyisi Technology Co., Ltd., Beijing, China; super clean bench from Chongqing Pharmaceutical Co., Ltd. Keyihuabo Branch Company, Chongqing, China; ultralow temperature refrigerator from Thermo Fisher Scientific, Inc. Operations were performed strictly in accordance with the respective instructions.

Specimen collection and processing. Two rats were anaesthetised with pentobarbital sodium $(30 \mathrm{mg} / \mathrm{kg})$ then sacrificed by cervical dislocation at 3, 6, 12, 24 and $48 \mathrm{~h}$ before and after burn, respectively (11). Abdominal aortic blood was collected from the animals, and frozen at $-20^{\circ} \mathrm{C}$ for testing after serum separation.

Construction of burn rat model. In the construction of the model, the back hair of rats was shaved, in an area of approximately $25 \mathrm{~cm}^{2}$. Anesthesia was intraperitoneally injected with $3.5 \%$ chloral hydrate $(10 \mathrm{ml} / \mathrm{kg})$, and then the YLS-5Q desktop super temperature control scald instrument was used to corporate burns. The wounds in 4 groups were the same, and the burned area was $20 \mathrm{~cm}^{2}$. The normal control group had no anesthesia and no burns. The hot conditions of model I group were: $90^{\circ} \mathrm{C}$ for temperature, $15 \mathrm{sec}$ for time and $1000 \mathrm{~g}$ for pressure. Those of model II group were: $80^{\circ} \mathrm{C}$ for temperature, $15 \mathrm{sec}$ for time and $1000 \mathrm{~g}$ for pressure. Those of model III group were: $80^{\circ} \mathrm{C}$ for temperature, $10 \mathrm{sec}$ for time and $500 \mathrm{~g}$ for pressure.

RT-PCR detection of expression of miR-184 and miR-126 in burned rats. After the above extraction of total mRNA in accordance with the real-time PCR kit instructions, the reverse transcription synthesis of cDNA was performed. Reaction was at $37^{\circ} \mathrm{C}$ for $45 \mathrm{~min}$ and at $95^{\circ} \mathrm{C}$ for $5 \mathrm{~min}$. The cDNA amplification reaction system was $20 \mu \mathrm{l}$ in total: pre-denaturation at $95^{\circ} \mathrm{C}$ for $10 \mathrm{~min}$, denaturation at $95^{\circ} \mathrm{C}$ for $10 \mathrm{sec}$, annealing at $60^{\circ} \mathrm{C}$ for $20 \mathrm{sec}$ and extension at $72^{\circ} \mathrm{C}$ for $10 \mathrm{sec}$, for a total of 40 cycles, and then extension at $72^{\circ} \mathrm{C}$ for 5 min after the completion of the cycle. U6 was used as a reaction internal reference. All the samples were repeated for 3 wells. The results were analyzed by $2^{-\mathrm{ACq}}$ method (12). The primers for RT-qPCR were synthesized by Suzhou Hongxun Biotechnology Co., Ltd., and the primer sequences are shown in Table I.

ELISA. ELISA was used to detect the expression levels of miR-184 and miR-126 in peripheral blood. The detection method referred to the kit instructions. The miR-184 and miR-126 detection kits were purchased from Shanghai Jingkang Bioengineering Co., Ltd., Shanghai, China.

Observation indicators. The changes of miR-184 and miR-126 levels were detected after operation, before modeling, at 3, 6, 12,24 and $48 \mathrm{~h}$ after burn. The relationship between miR-184 and $\mathrm{miR}-126$ and the burn degree of rats was observed, and the correlation between miR-184 and miR-126 analyzed.

Statistical analysis. SPSS21.0 statistical software package (Shanghai Kabei Information Technology Co., Ltd., Shanghai, China) was used for the statistical analysis of data. Measurement data were expressed as (mean \pm SD). The t-test was used for comparison between two groups, and F test for comparison among multiple groups. $\mathrm{P}<0.05$ was considered to indicate a statistically significant difference.

\section{Results}

Expression level of $m i R-184$. The results of analysis of variance showed that there was a difference in the 4 groups of rats in the expression level of miR-184 at 3, 6, 12, 24 and $48 \mathrm{~h}$ after burn $(\mathrm{P}<0.05)$, but no difference before modeling ( $P>0.05)$. Those of miR-184 at 3, 6, 12, 24 and $48 \mathrm{~h}$ after burn decreased compared with those before modeling in groups I, II and III $(\mathrm{P}<0.05)$. Those of miR-184 at $24 \mathrm{~h}$ and $48 \mathrm{~h}$ after burn were higher than those at $6 \mathrm{~h}$ after burn in groups I, II and III $(\mathrm{P}<0.05)$, and those of miR-184 at $48 \mathrm{~h}$ after burn were higher than those at $12 \mathrm{~h}$ after burn in groups I, II and III $(\mathrm{P}<0.05)$. There was no significant difference in the expression level of miR-184 among 4 time points in the control group $(\mathrm{P}>0.05)$. At the same time point, that of miR-184 decreased with the increase of burn degree. The expression levels of miR-184 were lower in groups I, II and III than those in control group 
Table II. RT-qPCR detection of expression level of miR-184.

\begin{tabular}{|c|c|c|c|c|c|c|}
\hline Groups & Control group & Group I & Group II & Group III & F value & $\mathrm{P}$-value \\
\hline Before modeling & $3.41 \pm 0.95$ & $3.45 \pm 0.94$ & $3.48 \pm 0.83$ & $3.45 \pm 0.94$ & 0.013 & 0.998 \\
\hline $3 \mathrm{~h}$ & $3.44 \pm 1.10$ & $1.85 \pm 0.82$ & $1.76 \pm 0.63$ & $1.25 \pm 0.51$ & 8.143 & 0.001 \\
\hline $6 \mathrm{~h}$ & $3.25 \pm 0.71$ & $0.67 \pm 0.54$ & $1.01 \pm 0.51$ & $1.22 \pm 0.25$ & 7.791 & 0.002 \\
\hline $12 \mathrm{~h}$ & $3.01 \pm 0.72$ & $0.73 \pm 0.28$ & $1.01 \pm 0.38$ & $1.05 \pm 0.24$ & 8.180 & 0.001 \\
\hline $24 \mathrm{~h}$ & $3.47 \pm 0.58$ & $0.63 \pm 0.31$ & $0.82 \pm 0.21$ & $0.86 \pm 0.21$ & 10.351 & 0.004 \\
\hline $48 \mathrm{~h}$ & $3.51 \pm 0.57$ & $0.52 \pm 0.23$ & $0.63 \pm 0.39$ & $0.76 \pm 0.32$ & 8.242 & 0.001 \\
\hline F value & 0.342 & 10.362 & 11.3523 & 11.595 & & \\
\hline P-value & 0.885 & 0.001 & 0.001 & 0.001 & & \\
\hline
\end{tabular}
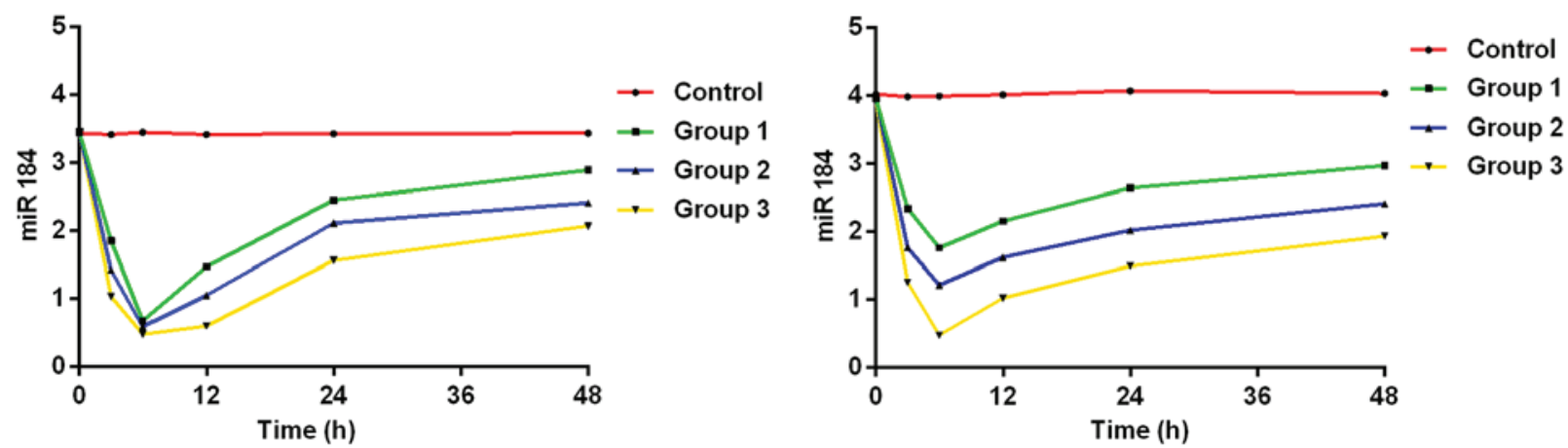

Figure 1. RT-qPCR and ELISA detection of expression level of miR-184. The results of two detection methods showed that the content of miR-184 in the control group was relatively stable. That of miR-184 in experimental group (groups I, II and III) showed the lowest value at $6 \mathrm{~h}$ after modeling, and then gradually increased $(\mathrm{P}<0.05)$. Note that time 0 in the figure is before modeling.
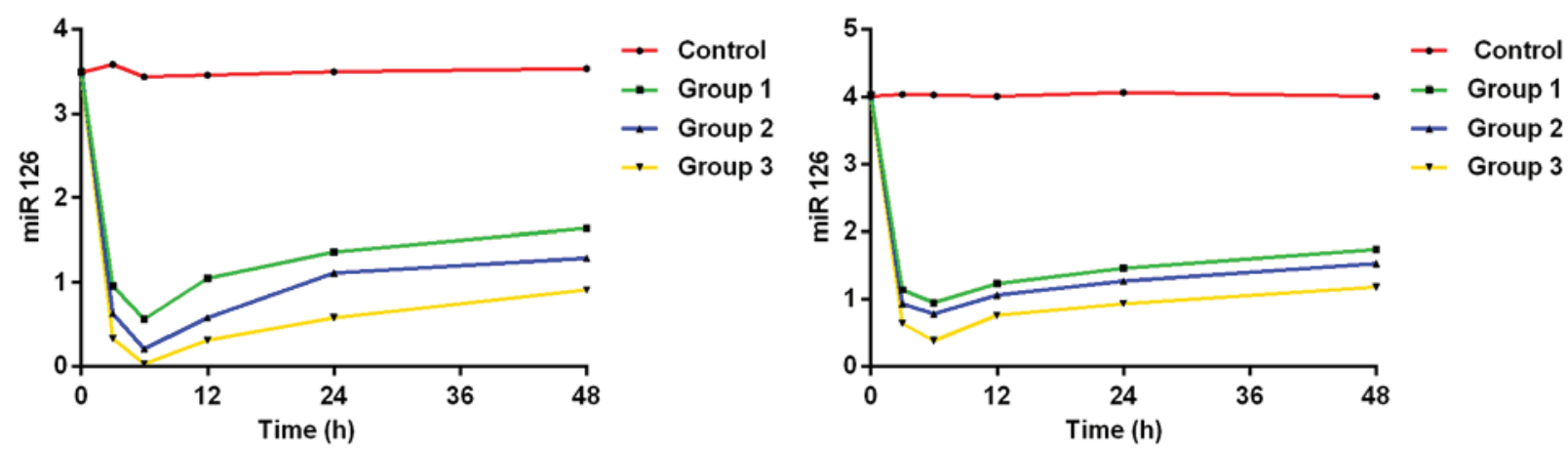

Figure 2. RT-qPCR and ELISA detection of expression level of miR-126. The results of two detection methods showed that the content of miR-184 in control group was relatively stable. That of miR-126 in experimental group (groups I, II and III) showed the lowest value at $6 \mathrm{~h}$ after modeling, and then gradually increased $(\mathrm{P}<0.05)$. Note that time 0 in the figure is before modeling.

at each time point $(\mathrm{P}<0.05)$, those of miR-184 were lower in groups II and III than those in group I $(\mathrm{P}<0.05)$, and that of miR-184 was lower in group III than that in group II $(\mathrm{P}<0.05)$. (Tables II and III, Fig. 1).

Expression level of miR-126. The results of analysis of variance showed that there was a difference among the four groups of rats in the expression level of miR-126 at 3, 6, 12, 24 and $48 \mathrm{~h}$ after operation $(\mathrm{P}<0.05)$, but no difference before modeling $(\mathrm{P}>0.05)$. Those of miR-126 at 3, 6, 12, 24 and $48 \mathrm{~h}$ after burn decreased compared with those before modeling in groups I, II and III $(\mathrm{P}<0.05)$. Those of miR-126 at 24 and $48 \mathrm{~h}$ after burn increased compared with those at $6 \mathrm{~h}$ after burn in groups I, II and III $(\mathrm{P}<0.05)$, and those of miR-126 at $12 \mathrm{~h}$ after burn decreased compared with those at $24 \mathrm{~h}$ after burn $(\mathrm{P}<0.05)$. There was no significant difference in the expression level of miR-126 among the four time points in control group $(\mathrm{P}>0.05)$. At the same time point, the expression level of miR-126 decreased with the increase of burn degree. The expression levels of miR-126 were lower in groups I, II and III than those in control group at each time point $(\mathrm{P}<0.05)$, those of miR-126 were lower in groups II and III than those in group I $(\mathrm{P}<0.05)$, and that of miR-126 was lower in group III than that in group II $(\mathrm{P}<0.05)$ (Tables IV and V, Fig. 2). 
Table III. ELISA detection of expression level of miR-184 (ng/ml).

\begin{tabular}{|c|c|c|c|c|c|c|}
\hline Groups & Control group & Group I & Group II & Group III & $\mathrm{F}$ value & P-value \\
\hline Before modeling & $3.81 \pm 0.55$ & $3.65 \pm 0.74$ & $3.68 \pm 0.63$ & $3.52 \pm 0.49$ & 0.161 & 0.922 \\
\hline $3 \mathrm{~h}$ & $3.74 \pm 1.12$ & $0.85 \pm 0.22$ & $1.76 \pm 0.84$ & $2.25 \pm 0.41$ & 14.201 & 0.001 \\
\hline $6 \mathrm{~h}$ & $3.85 \pm 0.61$ & $1.07 \pm 0.54$ & $1.41 \pm 0.61$ & $2.22 \pm 0.35$ & 13.248 & 0.001 \\
\hline $12 \mathrm{~h}$ & $4.01 \pm 0.42$ & $0.63 \pm 0.26$ & $1.11 \pm 0.33$ & $2.06 \pm 0.34$ & 14.120 & 0.001 \\
\hline $24 \mathrm{~h}$ & $4.07 \pm 0.28$ & $0.67 \pm 0.26$ & $0.92 \pm 0.51$ & $1.56 \pm 0.71$ & 14.365 & 0.001 \\
\hline $48 \mathrm{~h}$ & $4.01 \pm 0.47$ & $0.57 \pm 0.23$ & $0.73 \pm 0.44$ & $1.36 \pm 0.62$ & 12.364 & 0.001 \\
\hline F value & 0.524 & 17.052 & 14.682 & 15.524 & & \\
\hline P-value & 0.781 & 0.001 & 0.001 & 0.0001 & & \\
\hline
\end{tabular}

Table IV. RT-qPCR detection of expression level of miR-126.

\begin{tabular}{lcccrr}
\hline Groups & Control group & Group I & Group II & Group III & t value \\
\hline Before modeling & $3.48 \pm 0.21$ & $3.59 \pm 0.32$ & $3.64 \pm 0.41$ & $3.38 \pm 0.35$ & 0.264 \\
$3 \mathrm{~h}$ & $3.58 \pm 0.31$ & $0.59 \pm 0.08$ & $0.63 \pm 0.03$ & $0.75 \pm 0.07$ & 13.332 \\
$6 \mathrm{~h}$ & $3.23 \pm 0.21$ & $0.56 \pm 0.04$ & $0.56 \pm 0.05$ & $0.60 \pm 0.05$ & 14.253 \\
$12 \mathrm{~h}$ & $3.35 \pm 0.14$ & $0.50 \pm 0.06$ & $0.51 \pm 0.04$ & $0.54 \pm 0.06$ & 12.041 \\
$24 \mathrm{~h}$ & $3.49 \pm 0.31$ & $0.62 \pm 0.07$ & $0.65 \pm 0.07$ & $0.68 \pm 0.08$ & 13.542 \\
$48 \mathrm{~h}$ & $3.63 \pm 0.44$ & $0.64 \pm 0.06$ & $0.74 \pm 0.04$ & $0.81 \pm 0.08$ & 10.367 \\
F value & 0.347 & 14.352 & 12.321 & 15.213 & 0.001 \\
P-value & 0.782 & 0.001 & 0.001 & 0.001 & 0.001 \\
\hline
\end{tabular}

Table V. ELISA detection of expression level of miR-126 (ng/ml).

\begin{tabular}{lcccrr}
\hline Groups & Control group & Group I & Group II & Group III & F value \\
\hline Before modeling & $3.81 \pm 0.55$ & $3.65 \pm 0.74$ & $3.68 \pm 0.63$ & $3.52 \pm 0.49$ & 0.256 \\
$3 \mathrm{~h}$ & $3.74 \pm 1.12$ & $2.05 \pm 0.52$ & $2.66 \pm 0.54$ & $2.86 \pm 0.51$ & 12.325 \\
$6 \mathrm{~h}$ & $3.85 \pm 0.61$ & $1.27 \pm 0.74$ & $1.81 \pm 0.71$ & $2.12 \pm 0.55$ & 15.238 \\
$12 \mathrm{~h}$ & $4.01 \pm 0.42$ & $0.93 \pm 0.56$ & $1.62 \pm 0.43$ & $1.82 \pm 0.54$ & 15.131 \\
$24 \mathrm{~h}$ & $4.07 \pm 0.28$ & $0.57 \pm 0.36$ & $0.72 \pm 0.41$ & $1.06 \pm 0.41$ & 13.383 \\
$48 \mathrm{~h}$ & $4.01 \pm 0.47$ & $0.47 \pm 0.25$ & $0.53 \pm 0.24$ & $0.47 \pm 0.25$ & 14.353 \\
$\mathrm{~F}$ & 0.893 & 14.262 & 14.203 & 10.251 & 0.001 \\
$\mathrm{P}$ & 0.881 & 0.001 & 0.001 & 0.0001 & 0.001 \\
\hline
\end{tabular}

Correlation analysis of miR-184 and $m i R-126$. The results of Pearson's correlation analysis showed that the expression level of miR-184 was positively correlated with that of miR-126 $(\mathrm{r}=0.832, \mathrm{P}=0.002)$. miR-184 and miR-126 were positively correlated with burn degree $(r=0.901, P=0.001, r=0.775$, $\mathrm{P}=0.001)$ and time after burn $(\mathrm{r}=0.732, \mathrm{P}=0.004, \mathrm{r}=0.753$, $\mathrm{P}=0.002)$.

\section{Discussion}

Large-area deep burns have serious effects on the body, causing varying degrees of damage to systems that maintain the balance and stability of the internal environment (13). The immune defense system is also affected, leading to serious disorders, which is mainly manifested as severe damage to cellular immune function (14). The immune system is the first activated body defense response. When immune cells release large amounts of pro-inflammatory factors, it releases anti-inflammatory factors that inhibit the excessive inflammation (15). However, lymphocyte injury has a great impact on the body's immune response (16). The correlation between the expression levels of miR-184 and miR-126 and burn degree in rats and time after burn was analyzed, to help clinically prevent burn wounds from deepening.

In this study, 3 rat models with different burn degrees were constructed. The changes of miR-184 and miR-126 levels in 
burned rats were detected before modeling, at 3, 6, 12, 24 and $48 \mathrm{~h}$ after burn. The results showed that the expression of miR-184 and miR-126 in burned rats significantly decreased, compared with normal rats, with the increase of burn degree $(\mathrm{P}<0.05)$. Therefore, it is speculated that with the increase of burn degree, a large number of inflammatory factors are secreted, downregulating the levels of miR-184 and miR-126 that have become markers for evaluating burn severity and apoptosis, preventing burn wounds from deepening. When the body is stimulated by burns, inflammatory factors are rapidly activated, reaching a peak in a relatively fast time. If the degree of inflammatory response in the body is moderate and the changes of inflammatory factor levels are limited, it is beneficial to protect the body and relieve body damage and infection. Conversely, it may cause secondary damage to the tissue, promoting disease development $(17,18)$. In this study, the expression levels of miR-184 and miR-126 continuously decreased with the prolongation of time after burn, and the apoptosis degree in rats was getting higher and higher, indicating that the inflammatory response of rats continues to increase, and the secondary injury of burn wounds deepens. The results of Pearson's correlation analysis showed that the expression level of miR-184 was positively correlated with that of miR-126 ( $\mathrm{r}=0.832, \mathrm{P}=0.002)$. miR-184 and miR-126 were positively correlated with burn degree $(r=0.901, P=0.001$, $\mathrm{r}=0.775, \mathrm{P}=0.001)$ and time after burn $(\mathrm{r}=0.732, \mathrm{P}=0.004$, $\mathrm{r}=0.753, \mathrm{P}=0.002)$. It was reported that reducing the expression levels of miR-184 and miR-126 can effectively improve retinal and corneal damage caused by alkali burn $(19,20)$. Qiu et al (21) have also reported that the elevated level of miR-126 increases the risk of sepsis in burn patients. Huang et al (22) have also reported that improving the levels of miR-184 and miR-126 can improve the cardiac systolic function in burn patients. Their conclusions are consistent with our hypothesis that improving the levels of miR-184 and miR-126 can protect burn patients. In this study, real-time PCR was used to detect the expressions of miR-184 and miR-126 in burned rats. It is speculated that they are not only present in blood. It was found that the expression of miR-184 is upregulated in other tissues, such as the brain (23). Therefore, miR-184 and miR-126 may participate in the process of neovascularization, but its specific mechanism of action needs further study and confirmation. We studied a burn rat model. The burn condition is different from that of the actual patient. Although SD rats have many similarities with humans, the conclusion cannot represent the results of clinical experiments. Therefore, our conclusions still require more clinical experimental data for confirmation.

In summary, the expression levels of miR-184 and miR-126 decrease in burned rats. The changes of their levels, as a reference standard for the clinical efficacy evaluation, may be used to evaluate burn degree, preventing burn wounds from deepening.

\section{Acknowledgements}

Not applicable.

\section{Funding}

No funding was received.

\section{Availability of data and materials}

The datasets used and/or analyzed during the current study are available from the corresponding author on reasonable request.

\section{Authors' contributions}

SX constructed burn rat model. YF performed PCR. TW and PX helped with ELISA. SX and YF were involved in the writing of the manuscript. All authors read and approved the final manuscript.

\section{Ethics approval and consent to participate}

This study was approved by the Ethics Committee of Ningbo No. 2 Hospital (Ningbo, China).

\section{Patient consent for publication}

Not applicable.

\section{Competing interests}

The authors declare that they have no competing interests.

\section{References}

1. Earley ZM, Akhtar S, Green SJ, Naqib A, Khan O, Cannon AR, Hammer AM, Morris NL, Li X, Eberhardt JM, et al: Burn injury alters the intestinal microbiome and increases gut permeability and bacterial translocation. PLoS One 10: e0129996, 2015.

2. Peterson JR, De La Rosa S, Sun H, Eboda O, Cilwa KE, Donneys A, Morris M, Buchman SR, Cederna PS, Krebsbach PH, et al: Burn injury enhances bone formation in heterotopic ossification model. Ann Surg 259: 993-998, 2014.

3. Liu L, Li X, Yang J, Chai J, Yu Y, Duan H, Song H, Feng R, Wang $\mathrm{T}$, Yin $\mathrm{H}$, et al: Comparison of systemic inflammation response and vital organ damage induced by severe burns in different area. Int J Clin Exp Pathol 8: 6367-6376, 2015.

4. Yu S, Shi M, Liu C, Liu Q, Guo J, Yu S and Jiang T: Time course changes of oxidative stress and inflammation in hyperoxiainduced acute lung injury in rats. Iran J Basic Med Sci 18: 98-103, 2015.

5. Ning J and Chang TM: Effects of homologous and heterologous stroma-free hemoglobin and polyhemoglobin on complement activation, leucocytes and platelets. Biomater Artif Cells Artif Organs 18: 219-232, 1990.

6. Zhang X, Xu J, Cai X, Ji L, Li J, Cao B, Li J, Hu D, Li Y, Wang $\mathrm{H}$, et al: Acute insulin resistance mediated by advanced glycation endproducts in severely burned rats. Crit Care Med 42: e472-e480, 2014.

7. Gu S, Xing C, Han J, Tso MO and Hong J: Differentiation of rabbit bone marrow mesenchymal stem cells into corneal epithelial cells in vivo and ex vivo. Mol Vis 15: 99-107, 2009.

8. Wu Q, Wang JH, Li ZQ, Ren JL and Wu YH: Expression of vascular endothelial growth factor in deep second-degree scald wounds in rats. Zhongguo Yi Xue Ke Xue Yuan Xue Bao 36: 650-653, 2014 (In Chinese).

9. Yao QJ, Jia CY, Chen B, Tang CW, Xu MD, Ding GB and Wang HT: Establishment of rat model of scalding with high pressure steam. Zhonghua Shao Shang Za Zhi 20: 168-170, 2004 (In Chinese).

10. Tian L, Gao J, Weng G, Yi H, Tian B, O'Brien TD and Guo Z: Comparison of exendin- 4 on beta-cell replication in mouse and human islet grafts. Transpl Int 24: 856-864, 2011.

11. Jiang X, Gao L, Zhang Y, Wang G, Liu Y, Yan C and Sun H: A comparison of the effects of ketamine, chloral hydrate and pentobarbital sodium anesthesia on isolated rat hearts and cardiomyocytes. J Cardiovasc Med (Hagerstown) 12: 732-735, 2011. 
12. Livak KJ and Schmittgen TD: Analysis of relative gene expression data using real-time quantitative PCR and the 2(-Delta Delta C(T)) method. Methods 25: 402-408, 2001.

13. Chen Y, Yang W, Zhang X, Yang S, Peng G, Wu T, Zhou Y, Huang C, Reinach PS, Li W, et al: MK2 inhibitor reduces alkali burn-induced inflammation in rat cornea. Sci Rep 6: 28145, 2016

14. Quintana HT, Bortolin JA, da Silva NT, Ribeiro FA, Liberti EA, Ribeiro DA and de Oliveira F: Temporal study following burn injury in young rats is associated with skeletal muscle atrophy, inflammation and altered myogenic regulatory factors. Inflamm Res 64: 53-62, 2015.

15. Ge HW, Hu WW, Ma LL and Kong FJ: Endoplasmic reticulum stress pathway mediates isoflurane-induced neuroapoptosis and cognitive impairments in aged rats. Physiol Behav 151: 16-23, 2015.

16. Feng SH, Liu Q, Zhao YJ, Shi Y and Wang Y: Repair of finger deep burn with the island skin flap nourished by the cutaneous nerve nutrient vessel of the dorsum of hand. Zhonghua Zheng Xing Wai Ke Za Zhi 21: 98-100, 2005 (In Chinese).

17. Cardoso AL, Bachion MM, Morais JM, Fantinati MS, Almeida VL and Lino RSJ: Adipose tissue stromal vascular fraction in the treatment of full thickness burns in rats. Acta Cir Bras 31: 578-585, 2016

18. Yan S, Liang D, Lin M, Li Y and Wang Z: Study on the rat models of corneal neovascularization induced by alkali burn. Yan Ke Xue Bao 21: 165-172, 2005 (In Chinese).
19. Bai Y, Bai X, Wang Z, Zhang X, Ruan C and Miao J: MicroRNA-126 inhibits ischemia-induced retinal neovascularization via regulating angiogenic growth factors. Exp Mol Pathol 91: 471-477, 2011.

20. Fang CH, Li BG, Fischer DR, Wang JJ, Runnels HA, Monaco JJ and Hasselgren PO: Burn injury upregulates the activity and gene expression of the $20 \mathrm{~S}$ proteasome in rat skeletal muscle. Clin Sci (Lond) 99: 181-187, 2000.

21. Qiu P, Yao K, Zhu L, Zhou C and Cheng J: Expression and significance of vascular endothelial growth factor in rat cornea after cautery with alkali. Zhonghua Yan Ke Za Zhi 38: 311-314, 2002 (In Chinese).

22. Huang T, Zhang K, Sun L, Xue X, Zhang C, Shu Z, Mu N, Gu J, Zhang W, Wang Y, et al: Body protective compound-157 enhances alkali-burn wound healing in vivo and promotes proliferation, migration, and angiogenesis in vitro. Drug Des Devel Ther 9: 2485-2499, 2015.

23. Murad N, Kokkinaki M, Gunawardena N, Gunawan MS Hathout Y, Janczura KJ, Theos AC and Golestaneh N: miR-184 regulates ezrin, LAMP-1 expression, affects phagocytosis in human retinal pigment epithelium and is downregulated in agerelated macular degeneration. FEBS J 281: 5251-5264, 2014.

This work is licensed under a Creative Commons Attribution-NonCommercial-NoDerivatives 4.0 International (CC BY-NC-ND 4.0) License. 